\title{
A Study of the Biosynthesis of Phenazine-1-Carboxylic Acid
}

\author{
M. E. LEVITCH ${ }^{1,2}$ AND E. R. STADTMAN \\ From the Department of Dermatology, University of Michigan, Medical School, Ann Arbor, Michigan, and \\ National Heart Institute, National Institutes of Health, Bethesda, Maryland
}

Received December 16, 1963

\begin{abstract}
Washed cell preparations of Pseudomonas aureofaciens synthesize phenazine-1carboxylic acid in a medium consisting of $0.2 \mathrm{M}$ glycerol and $0.02 \mathrm{M}$ D, L-lysine. Experiments with $\mathrm{C}^{14}$-labeled substrates indicate that all of the carbon atoms in the phenazine-1-carboxylic acid are derived from glycerol. Anthranilic acid inhibits synthesis of this phenazine compound. Incorporation of label from $\mathrm{H}^{3}$-shikimic acid has been demonstrated. In addition, a decrease in the incorporation of label from glycerol-1,3-C14 into phenazine-1-carboxylic acid bas been demonstrated in the presence of unlabeled shikimic acid.
\end{abstract}

The genus Pseudomonas contains a number of species which produce characteristic pigments. The first pigment to be characterized (1) and certainly the one attracting the greatest interest has been pyocyanine (9- $N$-methyl-1-hydroxyphenazine), a blue compound produced by $P$ seudomonas aeruginosa. Burton et al. $(2,3)$ defined the nutritional requirements for production of pyocyanine by 4 -day growing cultures of $P$. aeruginosa. These workers found optimum production in a medium, containing glycerol, alanine, leucine, and salts. Studies on the incorporation of radioactive substrates into pyocyanine (4) provided some information about possible involvement, in early stages of the biosynthesis of pyocyanine, of a number of low molecular weight compounds. Labeled alanine and glycerol (either of which may serve as the major carbon source for the organism) are incorporated with comparatively good efficiency into the pigment.

A possible role of anthranilic acid as a

1 Part of this work was performed during tenure of a U. S. Public Health Service postdoctoral fellowship at the National Heart Institute, National Institutes of Health, Bethesda, Maryland.

2 This work was supported in part by grant GM-09869 from the U.S. Public Health Service. precursor in the biosynthesis of phenazine derivatives has been suggested in several recent publications. In a study of the effects of a number of aromatic compounds on pyocyanine production in $P$. aeruginosa, Kurachi $(5,6)$ found anthranilic acid to increase production of pigment and to reverse the inhibition exhibited by a number of others. Furthermore he presented evidence for the accumulation of anthranilic acid in the inhibited cultures. Other investigators (7) have studied the incorporation of radioisotope from anthranilic acid (carboxy-C ${ }^{14}$ ) into chlororaphin (the semiquinone of phenazine-1-carboxamide) produced by Pseudomonas chlororaphis.

The results reported in the present communication were obtained with an organism, Pseudomomas aurenfaciens $(8,9)$, which provides a biological system especially suited for a study of phenazine biosynthesis. Relatively large quantities (1 gm per liter) of the yellow pigment, phenazine-1-carboxylic acid, are produced by growing cultures of $P$. aureofaciens. The nutritional requirements for optimal production of phenazine1-carboxylic acid are defined, and some preliminary experiments designed to elucidate the mechanism of biosynthesis of this compound are describcd. 


\section{MATERIALS AND METHODS}

\section{Methods}

Pseudomonas aureofaciens, NRRL-B1543, was obtained from Dr. William Haynes of the Northern Regional Research Laboratory of the U.S. Department of Agriculture. A mutant of this organism has been isolated (designated strain $O R$ ), and was used in some of the studies. The stock cultures were carried on slants of the following medium: yeast extract (Difco), 1\%; glucose, 1\%; agar, $2 \%$; distilled water; pII adjusted to $7.7(8)$.

The liquid culture medium had the following composition: peptone (Difco), $2 \%$; glucose, $1 \%$; salt solution, $0.5 \%$, v $/ \mathrm{v}$ (per liter: $40 \mathrm{gm} \mathrm{MgSO}_{4}$. $7 \mathrm{H}_{2} \mathrm{O}, 2 \mathrm{gm} \mathrm{FeSO} \cdot 7 \mathrm{H}_{2} \mathrm{O}, 1.1 \mathrm{gm} \mathrm{MnCl}_{2} \cdot 4 \mathrm{H}_{2} \mathrm{O}$ ), $\mathrm{K}_{2} \mathrm{HPO}_{4}, 0.5 \%$; distilled water; $\mathrm{pH}$ adjusted to 7.0. Flasks containing $10 \mathrm{ml}$ of sterile growth medium are inoculated from slants and incubated on a rotary shaker at $30^{\circ} \mathrm{C}$ for 12 hours. These primary inocula are then used to inoculate larger amounts of medium; $0.2 \%$ inoeula are usually employed. The cells are harvested by centrifugation, washed with distilled water, then buffer, and finally suspended in buffer, $\mathrm{pH}$ 7. Cell yields are approximately $4 \mathrm{gm}$ wet weight per liter. In the original experiments with washed cells, $0.01 M$ phosphate buffer was used. Since the phosphate proved to inhibit pigment synthesis, sodium 3,3-dimethylglutarate bufier, $\mathrm{pH} 7$, was used in later experiments. The cell suspensions were made up to a final concentration of $200 \mathrm{mg}$ wet weight per milliliter. The standard incubation mixture for synthesis of pigment with washed cells consists of $0.2 \mathrm{M}$ glycerol plus $0.02 M \mathrm{DL}$-lysine.

For large scale production of the pigment, 200 liters of "pigment production" medium were inoculated with 15 liters of an actively growing culture in a 400 -liter fermenter. The composition of the "production" medium (8) was: Difco peptone, $2 \%$; glycerol, $1 \% ; \mathrm{NaCl}, 0.5 \% ; \mathrm{KNO}_{3}, 0.1 \%$; tap water; $\mathrm{pH} 7.2$. The incubation was stopped after 90 hours at $30^{\circ} \mathrm{C}$ by addition of concentrated $\mathrm{H}_{2} \mathrm{SO}_{4}$ to $\mathrm{pH}$ 1. The cells containing the pigment were collected by centrifugation in a Sharples centrifuge, air-dried, and extracted as described below.

The standard incubation mixture for the study of pigment production by washed cell suspensions was: glycerol, $400 \mu$ moles; DL-lysine, $40 \mu$ moles; 3,3-dimethylglutarate buffer ( $\mathrm{pH} 7$ ), $40 \mu$ moles; cells (wet weight), $40 \mathrm{mg}$, in $2 \mathrm{ml}$ of distilled water. Reaction mixtures were incubated in 25 -ml Erlenmeyer flasks on a rotary shaker for 12 hours at $30^{\circ} \mathrm{C}$.

\section{Isolation and Characterization of Pigment}

The incubation mixture was acidified to $\mathrm{pH}$ 1-2 by the addition of concentrated $\mathrm{HCl}$, and centrifuged. Most of the pigment sedimented with the cells. The supernatant was poured off, and the pellet was triturated in acetone. The acetone extract was transferred to an Erlenmeyer flask and taken to dryness on a steam bath. The residue was extracted with chloroform and was combined with a chloroform extract of the supernatant liquid. The chloroform was washed twice with water, and then the pigment was extracted with $1 N$ aqueous $\mathrm{NaOH}$. The aqueous layer was then acidified with concentrated $\mathrm{HCl}$, and the pigment extracted back into chloroform. This process was repeated twice. Phenazine-1-carboxylic acid was routinely assayed spectrophotometrically at 365 $\mathrm{m} \mu$. The acid crystallizes from $95 \%$ ethyl alcohol in long yellow needles. The material which had been recrystallized three times from $95 \%$ ethyl alcohol melted at $242^{\circ}-243^{\circ} \mathrm{C}$ (uncorrected), and no depression of the melting point was obtained when this material was mixed with an "authentic", sample. Also, the two samples exhibited identical infrared spectra.

\section{Radionctivity Determinations}

Radioactive phenazine-1-carboxylic acid, isolated as above, was recrystallized to constant specific activity from $95 \%$ ethyl alcohol. This material was dissolved in acetone and plated on ridged melal planchets, and counted at infinite thinness in a gas-flow counter. As a check on the radioactivity determination of solid samples, some of the samples were combusted to $\mathrm{CO}_{2}$ and counted in a gas-phase proportional counter (10).

\section{Materials}

Glycerol-1,3-C ${ }^{14}$ and glycerol-2-C ${ }^{14}$ were obtained from Orlando Research Incorporated, Orlando, Florida. All other $\mathrm{C}^{14}$-labeled compounds were obtained from New England Nuclear Corporation, Boston, Massachusetts. The shikimic$\mathrm{H}^{3}$ acid was a gift from Dr. R. Suhadolnik.

\section{RESULTS}

Optimal conditions for pigment production by washed cell preparations were determined. Table I illustrates the relative effectiveness of various substrates as carbon

${ }^{3}$ A gift from Dr. Frank Stodola of the Northern Regional Research Laboratory, United States Department of Agriculture, Peoria, Jllinois. 
TABLE I

Effectiveness of Various Carbon Sources for Pigment Production

Reaction mixture: $400 \mu$ moles of designated compound, $40 \mu$ moles of DL-lysine, $40 \mu$ moles of dimethylglutarate buffer ( $\mathrm{pH} 6.7$ ), and $40 \mathrm{mg}$. of cells (wet weight) in $2 \mathrm{ml}$.

\begin{tabular}{lc}
\hline Carbon source & $\begin{array}{c}\text { Phenazine-1-carboxylic } \\
\text { acid produced }(\mu \text { mole })\end{array}$ \\
\hline Glycerol & 0.190 \\
D-Glucose & 0.005 \\
D-Fructose & 0.55 \\
D-Ribose & 0.003 \\
DL-Lactic acid & 0.002 \\
Pyruvic acid & 0.008 \\
Succinic acid & 0.005 \\
D-Erythrose & 0.0 \\
D-Gluconic acid & 0.0 \\
\hline
\end{tabular}

TABLE II

Effectiveness of Amino Acids for Pigment Production

Reaction mixture: $400 \mu$ moles glycerol, 40 $\mu$ moles dimethyglutarate buffer ( $\mathrm{pH} 6.7$ ), $40 \mathrm{mg}$. cells (wet weight), $40 \mu$ moles of the appropriate amino acid, in $2 \mathrm{ml}$.

\begin{tabular}{lc}
\hline \multicolumn{1}{c}{ Arnino acid } & $\begin{array}{c}\text { Phenazine-1- } \\
\text { carboxylic acid } \\
\text { formed }(\mu \text { mole })\end{array}$ \\
\hline DL-Lysine & 0.74 \\
L-Arginine & 0.68 \\
DL-Valine & 0.63 \\
DL-Tyrosine & 0.60 \\
Glycine & 0.59 \\
L-Leucine & 0.40 \\
DL-Histidine & 0.30 \\
DL-Proline & 0.26 \\
L-Alanine & 0.23 \\
DL-Threonine & 0.18 \\
DL-Tryptophan & 0.08 \\
L-Cysteine & 0.06 \\
L-Methionine & 0.04 \\
DL-Phenylalanine & 0.04 \\
DL-Serine & 0.03 \\
L-Glutamic acid & 0.01 \\
L-Aspartic acid & 0.01 \\
\hline
\end{tabular}

sources for pigment production. Of the compounds tested, the greatest yield of pigment was obtained from glycerol; the only other compound yielding significant pigment was fructose. With glycerol as a substrate, various amino acids were tested for their ability to stimulate pigment pro- duction. As shown in Table II, lysine was the most effective nitrogen-containing compound tested, followed closely in order of decreasing effectiveness by arginine, valine, tyrosine, and glycine. The time course of pigment production by washed cells in a medium of glycerol and lysine is shown in Fig. 1. The $\mathrm{pH}$ optimum for pigment production is a rather broad one in the region of $\mathrm{pH} 7$. Figure 2 illustrates the growth response of the organism to the "growth" medium and the "glycerol-lysine" medium used for pigment production. It may be seen from Fig. 2 that the latter medium will not support growth.

\section{INHIBITION STUdies}

In an effort to find a metabolic inhibitor that would block one or more steps in the biosynthetic pathway, and possibly lead to the accumulation of identifiable intermediates, the influence of several aromatic compounds on pigment production was tested. Of numerous aromatic compounds examined, $o$-anisidine, aniline, $N$-formylaniline, acet-

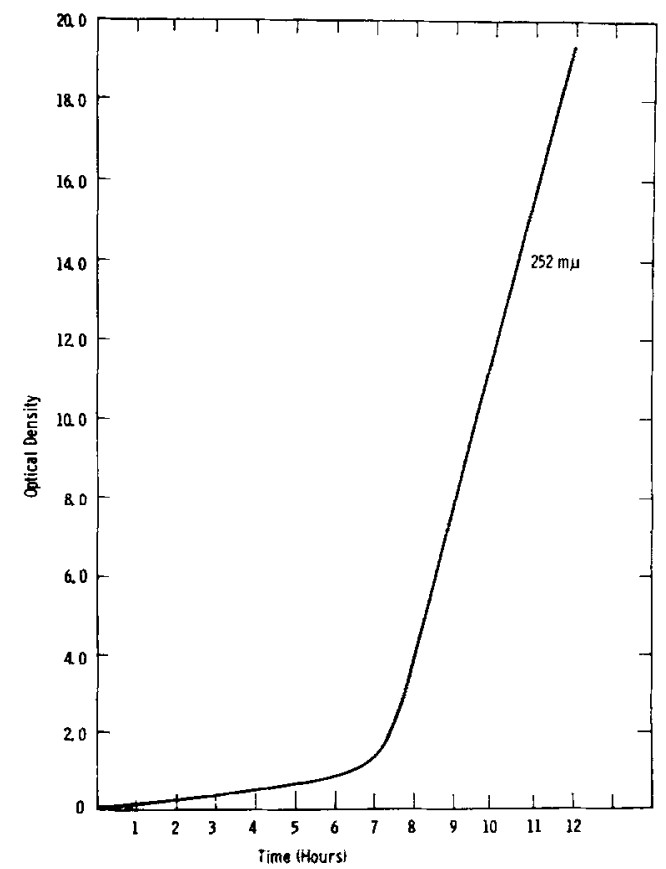

Fig. 1. The production of phenazine-1-carboxylic acid, as a function of time. The standard reaction mixture for pigment production with washed cells was used, as indicated in Methods. Pigment production is represented in terms of absorbance at $252 \mathrm{~m} \mu$. 


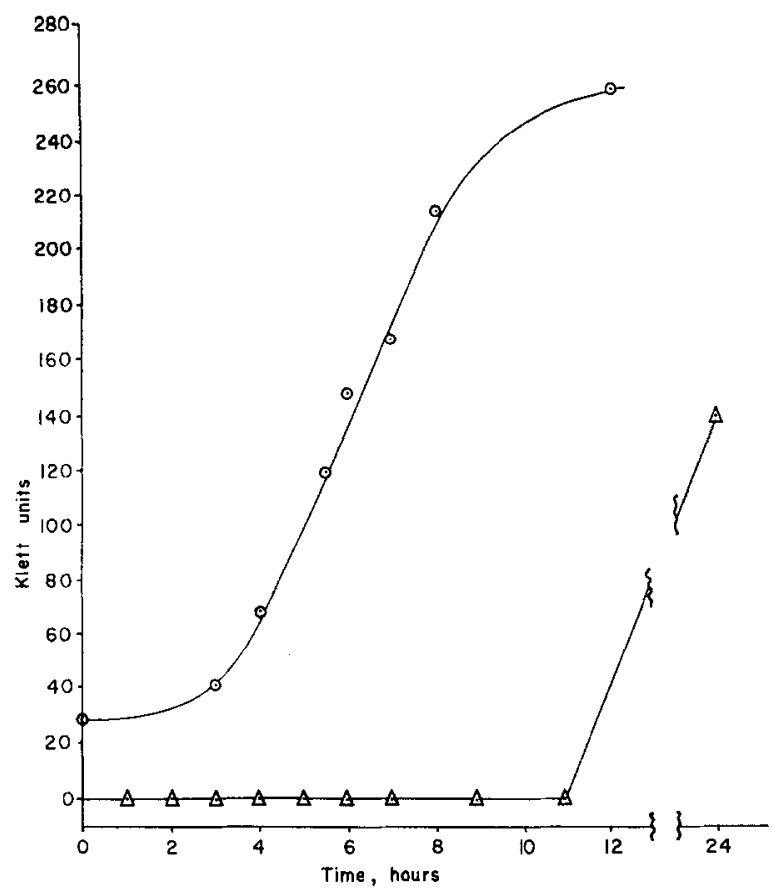

Fig. 2. Growth is plotted as a function of time. The upper curve represents growth in the growth medium, the lower curve in standard incubation mixture (see Methods). An actively growing culture of $P$. aureofaciens was centrifuged, washed with water, and a water suspension of the cells was used to inoculate the above media.

anilide, o-phenyledediamine, 2,3-dihydroxy quinoxaline, pyrogallol, $O$-aminophenol, and anthranilic acid inhibited pigment production completely when tested at concentrations of 6-10 $\mathrm{mM}$. Paper chromatography of cell filtrates, however, exhibited no new aromatic compounds accumulating in the medium. The method employed would not have detected the accumulation of an earlier nonaromatic precursor. Other inhibitors of pigment production in the resting cell suspensions were inorganic phosphate and glucose (Table III). The inhibition by anthranilic acid (Table III) was of special interest in view of indications by previous workers $(5,7)$ that anthranilic acid may be a precursor of pyocyanine. It can be seen that pigment synthesis is inhibited $50 \%$ by $2.5 \times 10^{-5} M$ and about $80 \%$ by $5 \times 10^{-5}$ $M$ anthranilic acid. No clear-cut reversal of this inhibition has been obtained, although an erratic partial reversal has been observed with shikimic acid. It should be mentioned that tryptophan, which is degraded to anthranilic acid in some biological systems,
TABLE III

Inhibition of Pigment Synthesis by Glucose and Phosphate

Each reaction mixture contained $400 \mu$ moles of glycerol, $40 \mu$ moles of DL-lysine, $40 \mu$ moles of so-

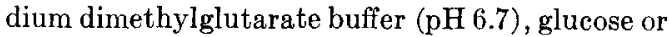
sodium phosphate as shown, and $40 \mathrm{mg}$. of cells (wet weight) in a final volume of $2 \mathrm{ml}$.

\begin{tabular}{lc}
\hline \multicolumn{1}{c}{ Additions $(\mu$ mole) } & $\begin{array}{c}\text { Phenazine-1-carboxylic } \\
\text { acid formed ( } \mu \text { mole) }\end{array}$ \\
\hline None & 1.14 \\
Glucose $(10)$ & 0.76 \\
Glucose (20) & 0.015 \\
Glucose (40) & 0.007 \\
None & \\
Phosphate (0.5) & 0.37 \\
Phosphate (1) & 0.23 \\
None & 0.00 \\
Anthranilic acid $(0.05)$ & 0.42 \\
Anthranilic acid $(0.1)$ & 0.21 \\
Anthranilic acid $(1.0)$ & 0.09 \\
\hline
\end{tabular}

also shows some activity as an inhibitor of pigment production. 
TABLE IV

Formation of Radioactive Phenazine-1-Carboxylic Acid from Radioactive Substrates

Each reaction mixture contained $400 \mu$ moles unlabeled glycerol, $40 \mu$ moles D L-lysine, $40 \mathrm{mg}$. cells, plus the appropriate radinactive compound in a total of $2 \mathrm{ml}$.

\begin{tabular}{|c|c|c|c|c|}
\hline & \multicolumn{2}{|c|}{ Substrate Added } & \multicolumn{2}{|c|}{ Phenazine-1-carboxylic acid formed } \\
\hline & $\mu \mathrm{c}$ & $\mu \mathrm{C} / \mu \mathrm{mole}$ & $\mu$ mole & $\mu \mathrm{c} / \mu \mathrm{mole}$ \\
\hline Glycerol-1,3-C 14 & 3 & $7.5 \times 10^{-3}$ & 0.30 & $3.1 \times 10^{-2}$ \\
\hline Glycerol-2-C & 2.86 & $6.9 \times 10^{-3}$ & 0.64 & $2.8 \times 10^{-2}$ \\
\hline Shikimic acid-U-H ${ }^{3}$ & 5.9 & 29 & 0.69 & $9.9 \times 10^{-3}$ \\
\hline Threnone-U-C ${ }^{14}$ & 5.0 & 1.0 & 0.74 & $9.7 \times 10^{-3}$ \\
\hline Acetate-2-C 14 & 5.0 & 1.0 & 0.10 & $3.8 \times 10^{-3}$ \\
\hline Succinate-2-C $\mathrm{C}^{14}$ & 5.0 & 2.5 & 0.83 & $3.6 \times 10^{-3}$ \\
\hline Pyruvate-2-C 14 & 5.0 & 1.8 & 0.71 & $1.1 \times 10^{-3}$ \\
\hline Alanine-2-C,14 & 2.8 & 1.3 & 0.72 & $6.4 \times 10^{-4}$ \\
\hline Histidine-2-C ${ }^{14}$ & 5.0 & 1.9 & 0.33 & $1.1 \times 10^{-4}$ \\
\hline Lysine-1-C $14 a$ & 1.88 & $3.76 \times 10^{-2}$ & 3.01 & 0.0 \\
\hline
\end{tabular}

${ }^{a}$ Reaction mixture contained $1000 \mu$ moles glycerol, $50 \mu$ moles lysine, and $200 \mathrm{mg}$. cells in $3 \mathrm{ml}$.

TABLE V

\section{ISOTOPE COMPETITION}

Reaction mixtures contained $0.1 \%$ glycerol, $1 \%$ peptone and Salts $\mathrm{B}$ (Methods) and glycerol$1,3-\mathrm{C}^{14}(423,000 \mathrm{cpm})$, plus the additions indicated, in a final volume of $10 \mathrm{ml}$. This medium was inoculated with an actively growing culture of $P$. aureofaciens and incubated for 24 hours.

\begin{tabular}{|c|c|c|c|c|}
\hline Additions & $\begin{array}{c}\text { Amount } \\
\text { added } \\
(\mu \text { mole })\end{array}$ & $\begin{array}{l}\text { Phenazine- } \\
\text { 1-carbox- } \\
\text { ylic acid } \\
\text { produced } \\
\text { ( } \mu \text { mole) }\end{array}$ & $\begin{array}{l}\text { Radio- } \\
\text { activity } \\
(\mathrm{cm} .)\end{array}$ & $\begin{array}{l}\text { Specific } \\
\text { radio- } \\
\text { activity } \\
\text { (cpm/ } \\
\text { umole) }\end{array}$ \\
\hline None & 一 & 1.6 & $1.26 \times 10^{4}$ & $7.0 \times 10^{3}$ \\
\hline $\begin{array}{l}\text { Shikimic } \\
\text { acid }\end{array}$ & 100 & 3.7 & $9.0 \times 10^{3}$ & $2.4 \times 10^{3}$ \\
\hline Threonine & 100 & 1.7 & $1.17 \times 10^{4}$ & $6.9 \times 10^{3}$ \\
\hline
\end{tabular}

\section{RAdioIsotope Studies}

In order to determine the saturating level of glycerol (which is employed in these experiments as the primary carbon source) different concentrations of glycerol (constant specific radioactivity) were used in the incubation mixtures. The results indicated saturation of the system by $0.2 M$ glycerol. This concentration of glycerol was used for all subsequent labeling experiments.

Various radioactive substrates were added to the standard incubation mixture and the incorporation of $\mathrm{C}^{14}$ or $\mathrm{H}^{3}$ into the phenazine-1-carboxylic acid was determined. These results are summarized in Table IV. Pigment from glycerol- $\mathrm{C}^{14}$ exhibited the highest specific radioactivity, followed closely by shikimic acid-U- $\mathrm{H}^{3}$ and threonine-C $\mathrm{C}^{14}$. All other radioactive substrates were much less efficient precursors of the phenazine-1-carboxylic acid. It should be noted that lysine1-C $\mathrm{C}^{14}$ did not label the pigment, indicating no contribution of carbon from carbon 1 of this amino acid. It may be recalled that a number of amino acids stimulated pigment production to an almost equal extent as did lysine, indicating no specific role for lysine in the biosynthesis of phenazine-1-carboxylic acid. This is supported by the labeling data. It will be noted that the specific radioactivity of phenazine-1-carboxylic acid derived from glycerol-1,3-C $\mathrm{C}^{14}$ is approximately 4 times that of the substrate, on a molar basis. Since the pigment contains thirteen carbon atoms and glycerol, three, the specific radioactivity per carbon atom of the substrate, glycerol-1,3-C $\mathrm{C}^{14}$, equals that of the phenazine-1-carboxylic acid. Therefore, all of the carbon atoms of the pigment must be derived from glycerol, with no contribution from lysine. The lysine may be acting as a nitrogen or energy source, or both.

If one or both of the aromatic carbocyclic rings in the phenazine-1-carboxylic acid is synthesized by the shikimic acid pathway, the addition of unlabeled shikimic acid to an incubation mixture containing $\mathrm{C}^{14}$-labeled glycerol should result in a decreased incorporation of $\mathrm{C}^{14}$ into pigment. The results of such an experiment are shown in Table V. A $70 \%$ decrease in the specific radioactivity of the product was observed 
upon the addition of unlabeled shikimic acid. 'Threonine also was tested in this experiment since threonine-U-C ${ }^{14}$ was incorporated into pigment with a relatively high efficiency. However, the relatively low dilution by unlabeled threonine makes questionable a direct role of this amino acid in the biosynthesis of phenazine-1-carboxylic acid.

\section{DISCUSSION}

Although the data presented in this paper are insufficient to suggest an actual pathway for the biosynthesis of phenazine-1-carboxylic acid, on strictly structural grounds one could visualize a condensation between an $o$-quinone and a derivative of $o$-phenylenediamine or an oxidative, self-condensation of some aromatic amine. Both processes are known nonenzymatic syntheses of phenazine compounds. One such hypothetical intermediate could be anthranilic acid. A similar condensation which has been shown to occur in a biological system is the self-condensation of 3-hydroxy-4-methylanthranilic acid to form the actinomycin chromophore, 2-aminophenoxazin-one-1,8-dicarboxylic acid (11). However, the evidence for a precursor role for anthranilic acid is not conclusive. Kurachi (5) obtained a threefold stimulation of pyocyanine biosynthesis by the addition of anthranilic acid at a concentration of $10^{-3} M$. In $P$. aureofaciens, biosynthesis of phenazine-1-carboxylic acid is completely inhibited by $10^{-3}$ $M$ anthranilic acid. Perhaps these two phenazine compounds are synthesized by totally different pathways. Another explanation for the inhibition by anthranilic acid in our system would involve a common intermediate for both anthranilic acid and phenazine-1-carboxylic acid. Feedback inhibition or repression of enzyme synthesis by anthranilic acid would then block pigment synthesis. A recently isolated compound, tentatively designated trans-2,3dihydro-3-hydroxy-anthranilic acid (12), could serve as such a dual intermediate.

More recently Carter and Richards (7) have suggested that anthranilic acid is a precursor of chlororaphin. These investi- gators incubated Pseudomonas chlororaphis for 5 days in a complex medium (glycerolpeptone-salts) with anthranilic acid (carboxy-C ${ }^{14}$, and obtained slight incorporation of the isotope. The data presented by these authors in support of a pathway of ehlororaphin biosynthesis involving shikimic acid, do not agree with the labeling patterns obtained in studies on shikimic acid in Escherichia coli mutants (13). Isotopic competition experiments show that incorporation of label from glycerol-1,3-C $\mathrm{C}^{14}$ into phenazine-1-carboxylic acid is decreased to $30 \%$ of the control value in the presence of unlabeled shikimic acid. Millican (14) demonstrated the incorporation of label from $\mathrm{C}^{14}$-labeled shikimic acid into pyocyanine. There is, then, at least presumptive evidence that one or both carbocyclic rings are synthesized by way of the shikimic acid pathway.

\section{RFFFRENCES}

1. Wrede, F., And Strack, E., Z. Physiol. Chent. 181, 58 (1929).

2. Burton, M. O., Eagles, B. A., and Campbell, J. J. R., Can. J. Res. C 25, 121 (1947).

3. Burton, M. O., Campbell, J. J. R., and Lagles, B. A., Can. J. Res. C 26, 15 (1948).

4. Blackwood, A. C., and Nersh, A. C., Can. J. Mierobiol. 3, 165 (1957).

5. Kurachi, M., Bull. Inst. Chem. Res., Kyoto Univ. 37, 85 (1959).

6. Kurachi, M., Bull. Inst. Chem. Res., Kyoto Univ. 37, 101 (1959).

7. Carter, R. E., and Richards, J. H., J. Am, Chem. Soc. 83, 495 (1961).

8. Haynes, W. C., Stonola, F. H., Locke, J. M., Pridham, T. G., Conway, H. F., Sohns, V. E., AND JACKson, R. W., J, Bacteriol. 72, 412 (1956).

9. Kluyver, A. V., J. Bacteriol. 72, 406 (1956).

10. Bernstein, W., and Baliantine, R., Rev. Sci. Instr. 21, 158 (1950).

11. Weissbach, H., And $K_{A t z}, \mathbf{E}$, J. Biol. Chem. 236, PC, 17 (1961).

12. McCormick, J. R. D)., Reichenthal, J., Hirsch, V., and Sjolander, N. O., $J$. Am. Chem. Soc. 83, 4104 (1961).

13. Srinivasan, P. R., Shigeura, H. T., SpreCher, M., Sprinson, D. B., and Davis, B. D., .f. Biol Chem 220, 477 (1956).

14. Millican, R. C., Biochem. Biophys. Acta 67, 407 (1962). 